\title{
Total synthesis of a Streptococcus pneumoniae serotype $12 F$ CPS repeating unit hexasaccharide
}

\author{
Peter H. Seeberger ${ }^{*} 1,2$, Claney L. Pereira ${ }^{3}$ and Subramanian Govindan ${ }^{1}$
}

\section{Full Research Paper}

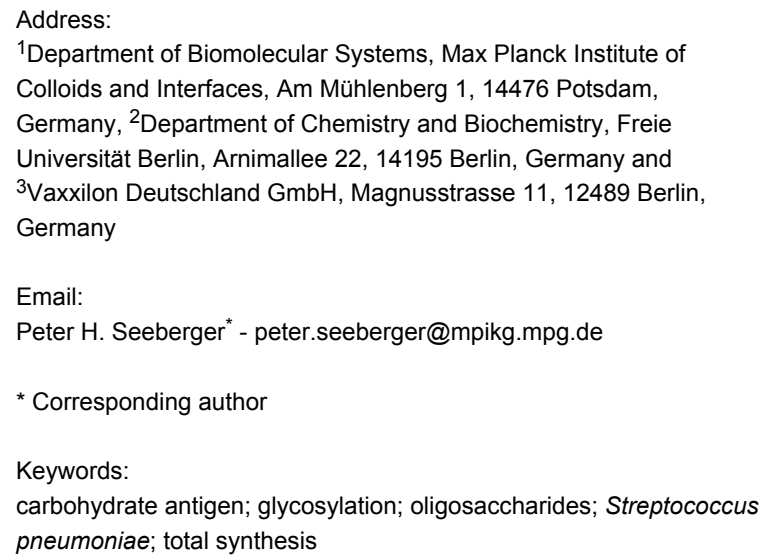

\author{
Beilstein J. Org. Chem. 2017, 13, 164-173. \\ doi:10.3762/bjoc.13.19
}

Received: 09 November 2016

Accepted: 01 January 2017

Published: 25 January 2017

Associate Editor: S. Flitsch

(C) 2017 Seeberger et al.; licensee Beilstein-Institut. License and terms: see end of document.

\begin{abstract}
The Gram-positive bacterium Streptococcus pneumoniae causes severe disease globally. Vaccines that prevent S. pneumoniae infections induce antibodies against epitopes within the bacterial capsular polysaccharide (CPS). A better immunological understanding of the epitopes that protect from bacterial infection requires defined oligosaccharides obtained by total synthesis. The key to the synthesis of the $S$. pneumoniae serotype $12 \mathrm{~F}$ CPS hexasaccharide repeating unit that is not contained in currently used glycoconjugate vaccines is the assembly of the trisaccharide $\beta$-D-Gal $p$ NAc- $(1 \rightarrow 4)-[\alpha-\mathrm{D}-\mathrm{Glc} p-(1 \rightarrow 3)]-\beta$-D-Man $p \mathrm{NAcA}$, in which the branching points are equipped with orthogonal protecting groups. A linear approach relying on the sequential assembly of monosaccharide building blocks proved superior to a convergent [3+3] strategy that was not successful due to steric constraints. The synthetic hexasaccharide is the starting point for further immunological investigations.
\end{abstract}

\section{Introduction}

Streptococcus pneumoniae is a Gram-positive bacterium that colonizes the upper respiratory tract and causes life-threatening pulmonary diseases as well as infections of the brain, the middle ear and the sinuses [1-6]. Twenty-three of the more than ninety $S$. pneumoniae serotypes, which differ in the capsular polysaccharides (CPS) that surround them, are responsible for about $90 \%$ of infections worldwide [7]. The licensed polysaccharide vaccine Pneumovax 23 contains serotype 12F but is not efficacious in young children or elderly people, those at highest risk. The carbohydrate conjugate vaccines Prevanar $13^{\mathrm{TM}}$ and Synflorix ${ }^{\mathrm{TM}}$ [8-11] are based on CPS-carrier protein constructs and contain thirteen or ten $S$. pneumoniae serotypes, respective- 
ly, but not $12 \mathrm{~F}[12,13]$. The $S$. pneumoniae serotypes 12A [14] and $12 \mathrm{~F}$ [15] combined account for more than $4 \%$ of pneumococcal disease [16], whereby $12 \mathrm{~F}$ (Figure 1) dominates with $85 \%$ [17]. In order to improve current glycoconjugate vaccines additional serotypes such as $12 \mathrm{~F}$ should be included in nextgeneration preparations [18].

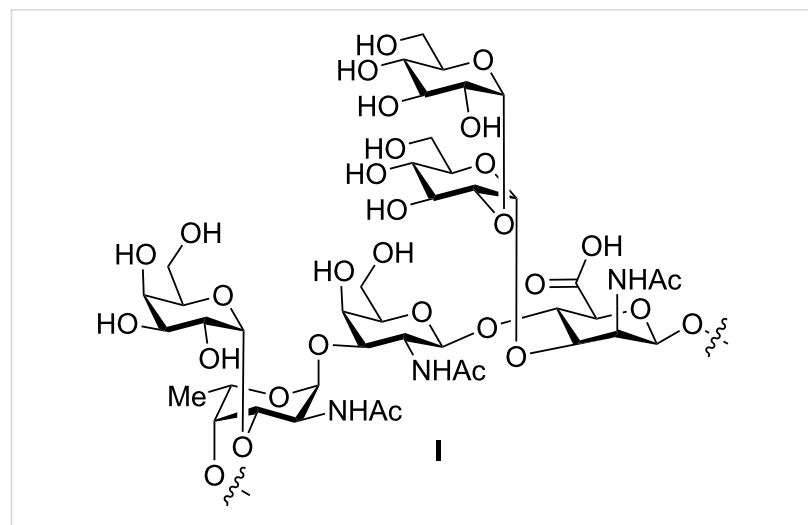

Figure 1: Structure of the S. pneumoniae serotype 12F capsular polysaccharide repeating unit [15].

Synthetic oligosaccharides are important tools for the identification of vaccine epitopes and have been the key to the creation of monoclonal antibodies that serve as tools for vaccine design
[19] and for the detection of pathogenic bacteria such as Bacillus anthracis [20,21]. S. pneumoniae 12F CPS consists of hexasaccharide repeating units containing the $[\rightarrow 4)-\alpha-\mathrm{L}-$ Fuc $p$ NAc- $(1 \rightarrow 3)-\beta-D-G a l p N A c-(1 \rightarrow 4)-\beta-D-M a n p N A c A-(1 \rightarrow]$ polysaccharide backbone with a disaccharide branch at $\mathrm{C} 3$ of $\beta$-D-Man $p$ NAcA and C3 of $\alpha$-L-Fuc $p$ NAc [15]. We established a total synthesis of the hexasaccharide repeat unit as a first step toward a detailed immunological analysis of $S$. pneumoniae $12 \mathrm{~F}$.

\section{Results and Discussion}

Retrosynthetic analysis. Initially, a convergent [3 + 3] synthesis of the repeating unit hexasaccharide 1 was envisioned. The union of trisaccharides $\mathbf{2}$ and $\mathbf{3}$ (Scheme 1, route A) was identified as the key step. The outcome of this late-stage block coupling was deemed risky considering the poor nucleophilicity of the $\mathrm{C} 4$ hydroxy group of the $\beta$-mannosazide in $\mathbf{3}$ combined with steric bulk around the acceptor. Trisaccharides $\mathbf{2}$ and $\mathbf{3}$ can be derived from differentially protected common building blocks that carry tert-butyldimethylsilyl (TBS), benzoate (Bz) or acetate (Ac) ester and 2-naphthylmethyl (NAP) protecting groups that can be removed sequentially to allow for glycosylation of the liberated hydroxy groups. Formation of the $\beta$-mannosazide glycoside containing a protected $\mathrm{C}_{5}$ amino linker that serves in the final product as an attachment point for

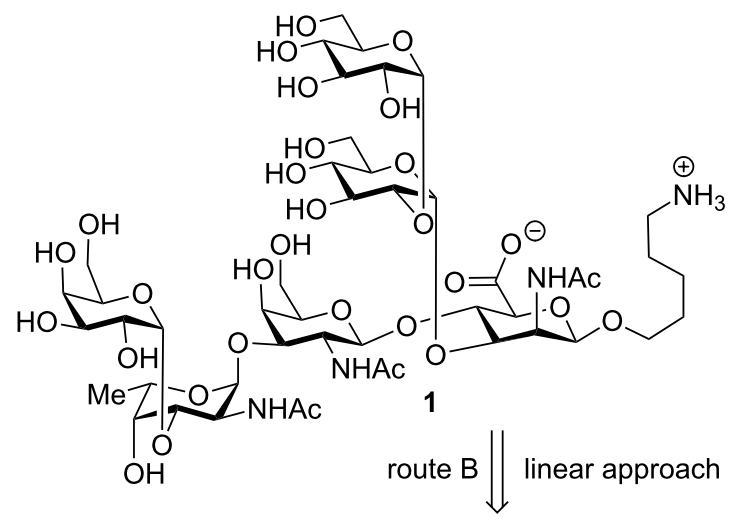

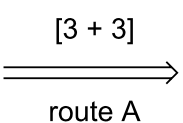

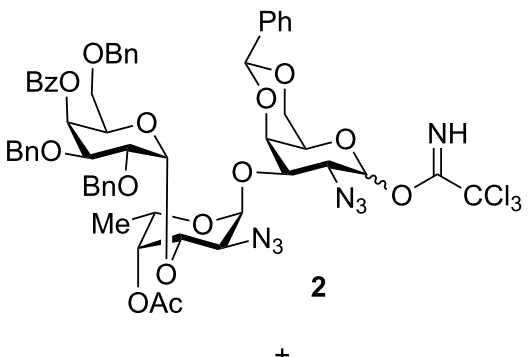

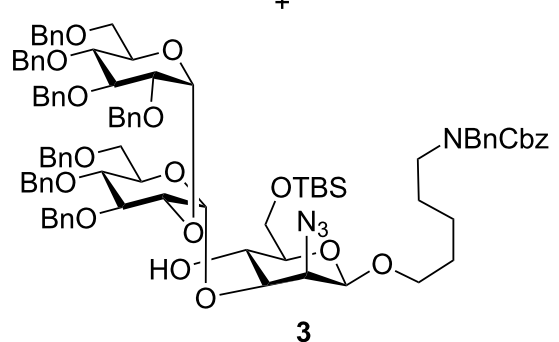

3

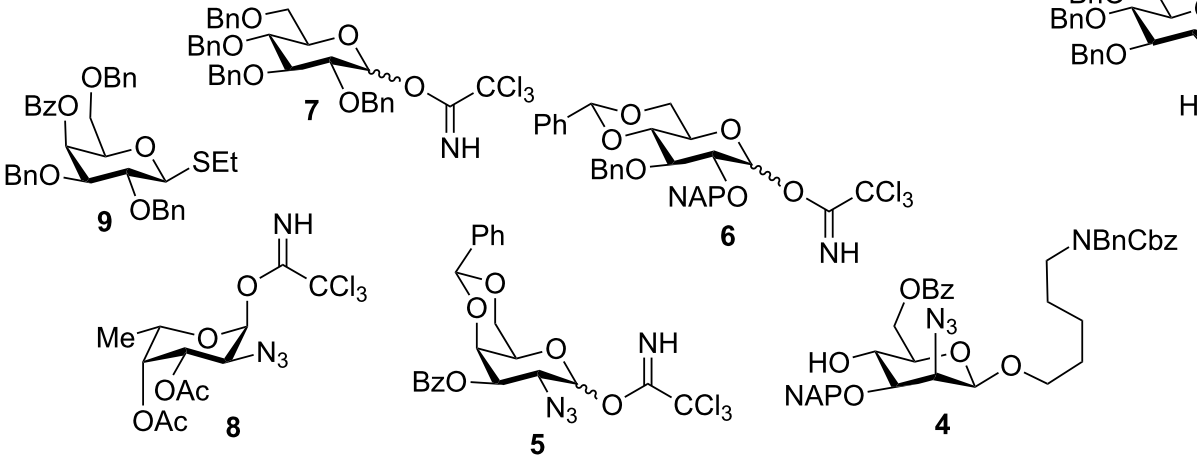


glycan array surfaces or carrier proteins was central to the assembly of trisaccharide 3 . To avoid a challenging and often unselective $\beta$-mannoside formation step we resorted to glucose-mannose conversion by inversion of the $\mathrm{C} 2$ stereocenter following selective installation of a trans-glucosidic linkage. Differentially protected thioglucoside 11 [22] is equipped with a participating C2 levulinyl ester that is replaced by an axial azido group following $\beta$-glucoside formation [23].

Alternatively, a linear synthetic strategy in which the sterically hindered C4 hydroxy group would be glycosylated first, followed by the $\mathrm{C} 3$ hydroxy group of $\beta$-mannosazide building block 4 , was designed in case the convergent approach proved unsuccessful (Scheme 1, route B).

Building block synthesis. The accessibility of differentially protected monosaccharide building blocks is a prerequisite for the successful total synthesis of any complex glycan. The synthesis of the mannosazide building block was the first challenge to be addressed. Installation of a C2-participating levulinyl ester protecting group ensured selective formation of the trans-glycoside upon activation of $\mathbf{1 1}$ by NIS/TfOH in the presence of the $\mathrm{C}_{5}$ linker to produce glucoside $\mathbf{1 2}$ in $70 \%$ yield [24]. Cleavage of the $\mathrm{C} 2$ levulinyl ester of $\mathbf{1 2}$ by treatment with hydrazine acetate furnished $\mathbf{1 3}$, which was to be carried forward into the $\mathrm{C} 2$ inversion step. Conversion of $\mathbf{1 3}$ to the corresponding $\mathrm{C} 2$ triflate upon treatment with triflic anhydride in pyridine was not successful. Even model thioglycoside $\mathbf{1 0}$ failed to react to the corresponding glycosyl triflate under similar conditions (Scheme 2).

The problems associated with the lengthy and low yielding synthetic sequence prompted us to explore a different approach to obtain the key mannosazide building block (Scheme 3). Partially protected mannosazide thioglycoside $\mathbf{1 6}$ was prepared in seven steps from $\alpha$-O-methylglucose following a published procedure [25]. Silylation of the $\mathrm{C} 3$ hydroxy group furnished thioglycoside 17. Glycosylation of the $\mathrm{C}_{5}$ linker by activation of 17 using NIS/TfOH as the promoter at $-20{ }^{\circ} \mathrm{C}$ produced mainly $\beta$-mannoside $15(4: 1 \beta: \alpha)$ [26]. The identity of the $\beta$-isomer was confirmed by NMR analysis $\left({ }^{1} J_{\mathrm{CH}} \beta=159.0 \mathrm{~Hz}\right.$, see Supporting Information File 1). Cleavage of the silyl ether by TBAF treatment of $\mathbf{1 5}$ afforded the $\beta$-mannosazide building block 18.

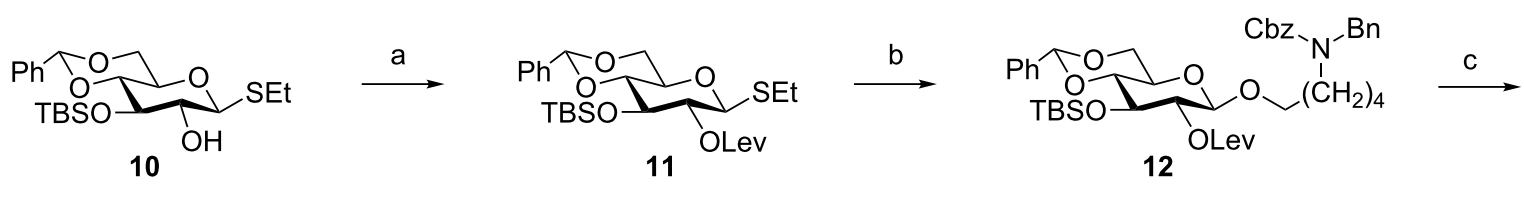

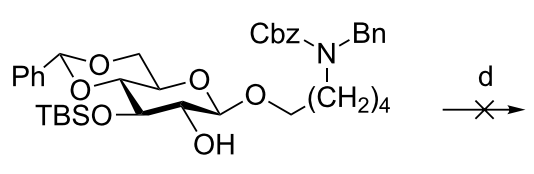

13

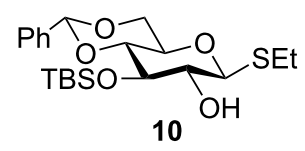

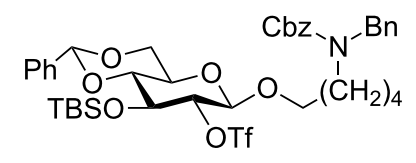

14

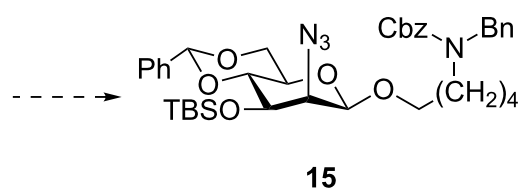

15

Scheme 2: Attempted synthesis of mannosazide building block 15. Reagents and conditions: (a) levulinic acid, DCC, DMAP, $\mathrm{CH}_{2} \mathrm{Cl} 2,82 \%$; (b) $\mathrm{NIS}$, $\mathrm{TfOH}, \mathrm{HO}\left(\mathrm{CH}_{2}\right)_{5} \mathrm{NBnCbz}, \mathrm{CH}_{2} \mathrm{Cl}_{2},-20^{\circ} \mathrm{C}, 70 \%$; (c) $\mathrm{N}_{2} \mathrm{H}_{4}, \mathrm{AcOH}$, pyridine, $\mathrm{CH}_{2} \mathrm{Cl}_{2}, 70 \%$; (d) $\mathrm{Tf}_{2} \mathrm{O}$, pyridine, $\mathrm{CH}_{2} \mathrm{Cl}_{2}, 0^{\circ} \mathrm{C}$ to rt.

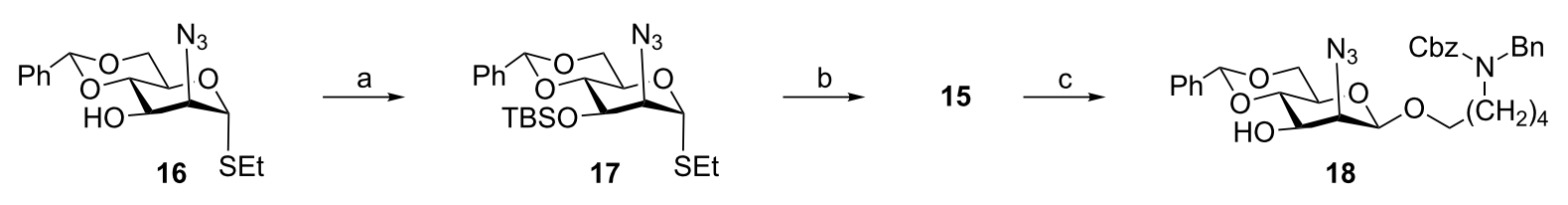

Scheme 3: Synthesis of mannosazide building block 18. Reagents and conditions: (a) TBSCl, imidazole, $\mathrm{DCM}, 0{ }^{\circ} \mathrm{C}$ to $\mathrm{rt}, 85 \%$; (b) $\mathrm{NIS}$, TfOH, $\mathrm{HO}\left(\mathrm{CH}_{2}\right)_{5} \mathrm{NBnCbz}, \mathrm{CH}_{2} \mathrm{Cl}_{2},-20^{\circ} \mathrm{C}, 61 \%$; (c) TBAF, THF, $0{ }^{\circ} \mathrm{C}, 80 \%$. 
Convergent $[3+3]$ synthesis. Synthesis of the reducing-end trisaccharide 3 (Scheme 1) commenced with the assembly of the $\alpha-1 \rightarrow 2$ linked diglucoside 19 by union of the monosaccharide building blocks $\mathbf{1 0}$ and 7 [27] in a dichloromethane-ether (enables alpha selectivity) mixture in $56 \%$ yield (Scheme 4 ). Removal of the silyl ether and benzylidene groups of $\mathbf{1 9}$ yielded triol 20 before benzylation afforded disaccharide thioglycoside building block 21. Activation of disaccharide 21 resulted in the glycosylation of mannosazide acceptor $\mathbf{1 8}$ (Scheme 3 ) to form the corresponding $\alpha$-linked trisaccharide, which, subsequent to removal of the 4,6-benzylidene group under acidic conditions, provided diol 22 that was in turn converted into reducing-end trisaccharide 3 by selective placement of a TBS ether [28] on the primary alcohol (Scheme 4).

With reducing-end trisaccharide $\mathbf{3}$ in hand, we turned our attention to the synthesis of trisaccharide 2 , which required the availability of three differentially protected monosaccharide building blocks: 8, 9 and 26 (Scheme 5). Protected building block 26 was obtained in four steps from known galactosylazide selenide 23 [29]. Acetylation of the C3 hydroxy group of $\mathbf{2 3}$ furnished fully differentially protected selenoglycoside 24 in $82 \%$ yield. Hydrolysis of the selenoglycoside using NIS in aqueous THF produced hemiacetal $\mathbf{2 5}$ that was silylated prior to selective saponification of the $\mathrm{C} 3 \mathrm{O}$-acetate to yield building block $\mathbf{2 6}$ (Scheme 5).

Fucosazide building block $\mathbf{8}$ was derived from diacetyl fucal $\mathbf{2 7}$ that in turn was prepared in two steps from L-fucose [30].
Azido-selenation of $\mathbf{2 7}$ and hydrolysis of the seleno fucosazide with NIS in aqueos THF [31] provided hemiacetal 28, which was subsequently converted to the fucosyl trichloroacetimidate building block 8 (Scheme 5). Galactosyl thioglycoside 9 was prepared from D-galactose following published procedures [32]. Reductive opening of the benzylidene acetal of known galactosyl thioglycoside 29 [33] with triethylsilane [34] in TFA/ $\mathrm{CH}_{2} \mathrm{Cl}_{2}$ liberated the $\mathrm{C} 4$ hydroxy group of $\mathbf{3 0}$, which was subsequently benzoylated to ensure remote participation in 9 for the preferential formation of cis-glycosides (Scheme 5) [35].

With the three building blocks $\mathbf{8 , 9}$ and 26 in hand, the assembly of the non-reducing end trisaccharide $\mathbf{2}$ commenced. The union of $\mathbf{8}$ and $\mathbf{2 6}$ produced the $\alpha$-linked disaccharide $\mathbf{3 1}$ in 74\% yield and excellent $\alpha$-selectivity due to remote participation of the $\mathrm{C} 2$ and $\mathrm{C} 3$ acetate esters present in the fucosazide donor (Scheme 6). Preparation of the site for the downstream glycosylation, the $\mathrm{C} 3$ hydroxy group in the fucosazide moiety, to obtain 35, required several protecting group manipulation steps: cleavage of the two acetate esters of $\mathbf{3 1}$ to produce diol $\mathbf{3 2}$ was followed by the reaction with trimethyl orthoacetate to provide the ortho-ester 33, which was regioselectively opened under acidic conditions to afford disaccharide acceptor $\mathbf{3 4}$ containing a C3 hydroxy group [28]. Glycosylation of disaccharide 34 using galactose building block $\mathbf{9}$, activated by NIS/triflic acid, produced trisaccharide 35 with high $\alpha$-selectivity by virtue of the C4-participating benzoyl ester protecting group of 9 [36]. Trisaccharide 35 was transformed into a glycosylating agent by
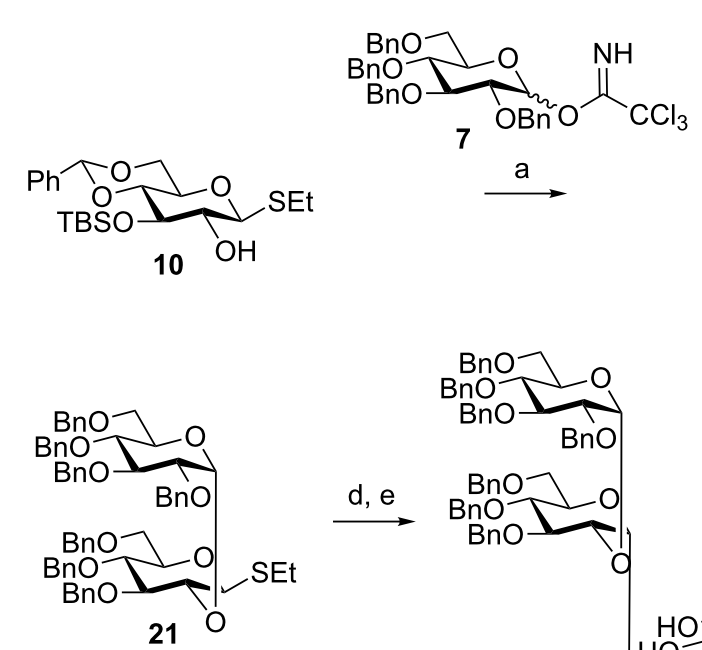
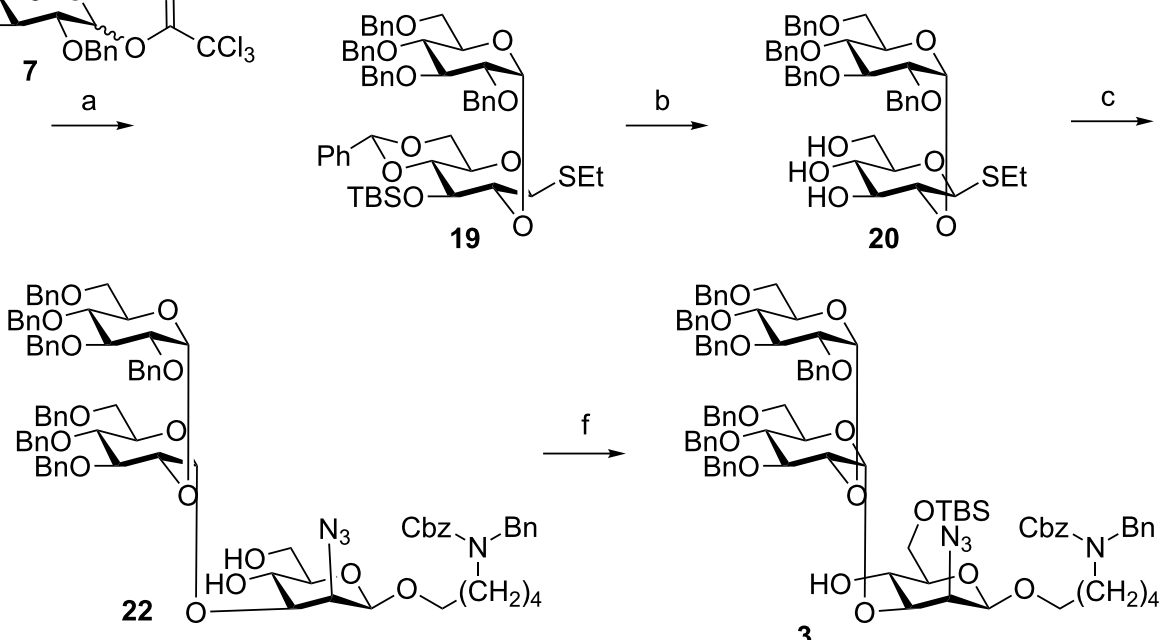

3

Scheme 4: Synthesis of the reducing-end trisaccharide 3. Reagents and conditions: (a) TMSOTf, $\left(\mathrm{CH}_{3} \mathrm{CH}_{2}\right)_{2} \mathrm{O} / \mathrm{CH}_{2} \mathrm{Cl}_{2}(4: 1),-20{ }^{\circ} \mathrm{C}, \alpha / \beta=4: 1,70 \%$; (b) $p$ - TsOH, $\mathrm{CH}_{3} \mathrm{OH} / \mathrm{CH}_{2} \mathrm{Cl}_{2}$ (1:1), rt, 70\%; (c) NaH, benzyl bromide, THF/DMF (1:1), $0{ }^{\circ} \mathrm{C}$ to rt, $90 \%$; (d) 18, NIS, TfOH, $\left(\mathrm{CH}_{3} \mathrm{CH}_{2}\right)_{2} \mathrm{O} / \mathrm{CH}_{2} \mathrm{Cl}_{2},(4: 1)$, $-20{ }^{\circ} \mathrm{C}, 61 \%$; (e) $p-\mathrm{TsOH}, \mathrm{CH}_{3} \mathrm{OH}, \mathrm{rt}, 90 \%$; (f) $\mathrm{TBSCl}$, imidazole, $\mathrm{CH}_{2} \mathrm{Cl}_{2}, \mathrm{rt}, 93 \%$. 

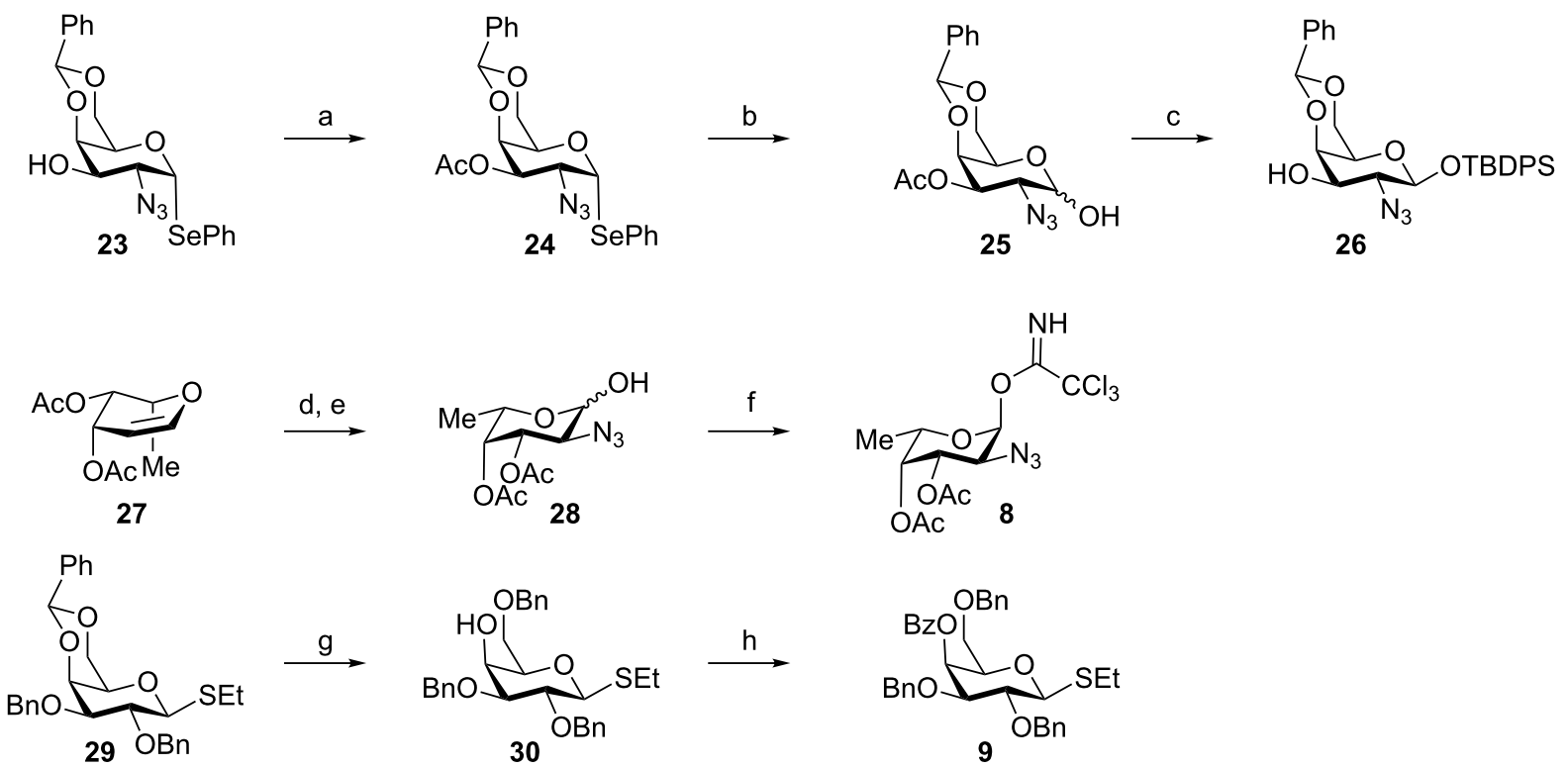

Scheme 5: Synthesis of monosaccharide building blocks 8,9 and 26. Reagents and conditions: (a) acetic anhydride, pyridine, $\mathrm{CH}_{2} \mathrm{Cl}_{2}, \mathrm{rt}, 18 \mathrm{~h}, 82 \%$; (b) NIS, THF/H $\mathrm{H}_{2} \mathrm{O}$ (1:1), rt; (c) 1) TBDPSCl, imidazole, DMF, rt; 2) NaOMe, $\mathrm{MOH}, \mathrm{rt}, 68 \%$ over two steps; (d) $(\mathrm{PhSe})_{2}, \mathrm{BAIB}^{\circ}, \mathrm{NaN}_{3}, \mathrm{CH}_{2} \mathrm{Cl}_{2}, \mathrm{rt}, 24 \mathrm{~h}$; (e) NIS, THF/H $\mathrm{H}_{2} \mathrm{O}(1: 1)$, rt, $80 \%$ over two steps; (f) $\mathrm{CCl}_{3} \mathrm{CN}, \mathrm{DBU}, \mathrm{CH}_{2} \mathrm{Cl}_{2}, 0{ }^{\circ} \mathrm{C}$ to rt, $2 \mathrm{~h}, 72 \%$; (g) TES, TFA, $\mathrm{CH}_{2} \mathrm{Cl}_{2}, 0{ }^{\circ} \mathrm{C}, 6 \mathrm{~h}$; (h) benzoyl chloride, pyridine, rt, $18 \mathrm{~h}, 80 \%$ over two steps.

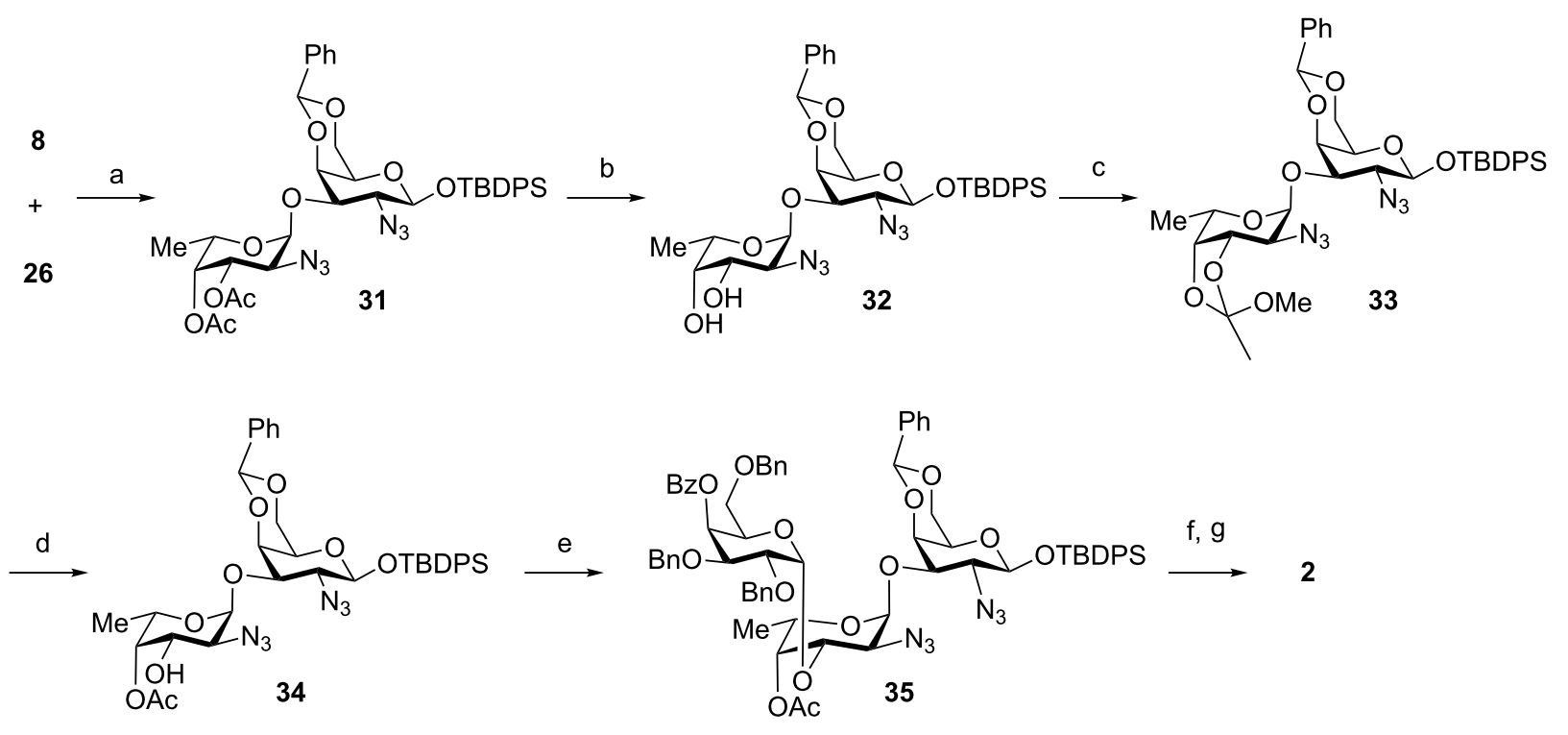

Scheme 6: Synthesis of the non-reducing end trisaccharide 2. Reagents and conditions: (a) TMSOTf, $\mathrm{CH}_{2} \mathrm{Cl}_{2},-30{ }^{\circ} \mathrm{C}, 74 \%$; (b) $\mathrm{NaOMe}(0.5 \mathrm{M}$ in $\mathrm{MeOH}), \mathrm{MeOH}$, rt; (c) trimethyl orthoacetate, $p-\mathrm{TsOH}$, toluene; (d) $80 \% \mathrm{AcOH}$, rt, $71 \%$ over three steps; (e) 9, NIS, TMSOTf, dioxane/toluene (3:1), $-10{ }^{\circ} \mathrm{C}, 54 \%$; (f) $\mathrm{HF}$-pyridine, $\mathrm{THF}, 0{ }^{\circ} \mathrm{C}$; (g) $\mathrm{CCl}_{3} \mathrm{CN}$, DBU, $\mathrm{CH}_{2} \mathrm{Cl}_{2}, 0{ }^{\circ} \mathrm{C}, 57 \%$ over two steps.

removal of the anomeric TBDPS silyl ether using HF-pyridine and subsequent treatment with trichloroacetonitrile in the presence of catalytic amounts of DBU to afford glycosyl trichloroacetimidate trisaccharide $\mathbf{2}$ (Scheme 1).
With trisaccharide fragments $\mathbf{2}$ and $\mathbf{3}$ in hand, the convergent $[3+3]$ approach (Scheme 1, route A) to the synthesis of the repeating unit hexasaccharide 36 (Scheme 7) was attempted. The union of trisaccharides $\mathbf{2}$ and $\mathbf{3}$ using TMSOTf in aceto- 
nitrile as the activator did not yield the desired hexasaccharide 36. Instead, trisaccharide acceptor 3 missing its C6 silyl ether protecting group $\mathbf{3 8}$ was recovered. The undesired outcome of this coupling step likely resulted from the poor nucleophilicity of $\mathbf{3}$ rather than a lack of reactivity of trisaccharide glycosylating agent $\mathbf{2}$, as demonstrated by an experiment in which model monosaccharide 37 [29] also failed to react with trisaccharide acceptor $\mathbf{3}$ and recovered $\mathbf{3 8}$ (Scheme 7).

In order to better understand the formation of the key disaccharide GalNAc $\rightarrow$ ManNAcA, a model glycosylation involving mannosazide 4 (Scheme 7, prepared in four steps from 16, see Supporting Information File 1) was explored. Differentially protected mannosazide 4 was successfully glycosylated using building blocks $\mathbf{5}$ or $\mathbf{3 7}$ to yield the corresponding disaccharide in $21 \%$ and $37 \%$ yield, respectively. The failure of the $[3+3]$ coupling to produce hexasaccharide $\mathbf{3 6}$ was apparently a result of the poor nucleophilicity of the C4 hydroxy group in $\mathbf{3}$ rather than of problems associated with the glycosylating agents. The presence of a disaccharide appendage at the $\mathrm{C} 3$ position as well as a bulky TBS silyl ether at C6 may block the C4 hydroxy group.

The $\beta$-selectivity of glycosylations using glycosylating agents $\mathbf{5}$ and $\mathbf{3 7}$ even in acetonitrile was rather poor. Apparently, the "nitrile effect" [37,38] is partially overruled by the participating nature of the $\mathrm{C} 3$ ester protecting groups $\mathrm{Ac} / \mathrm{Bz}$ that leads to a preference for the cis-glycosidic $\alpha$-linked product.

\section{Linear total synthesis of $12 \mathrm{~F}$ repeating unit hexasaccharide}

1. The failure of the convergent $[3+3]$ total synthesis approach prompted us to retreat to the linear avenue (Scheme 1, route B) towards the target oligosaccharide in order to avoid the sterically demanding late-stage glycosylation. Differentially pro-

A)

B)
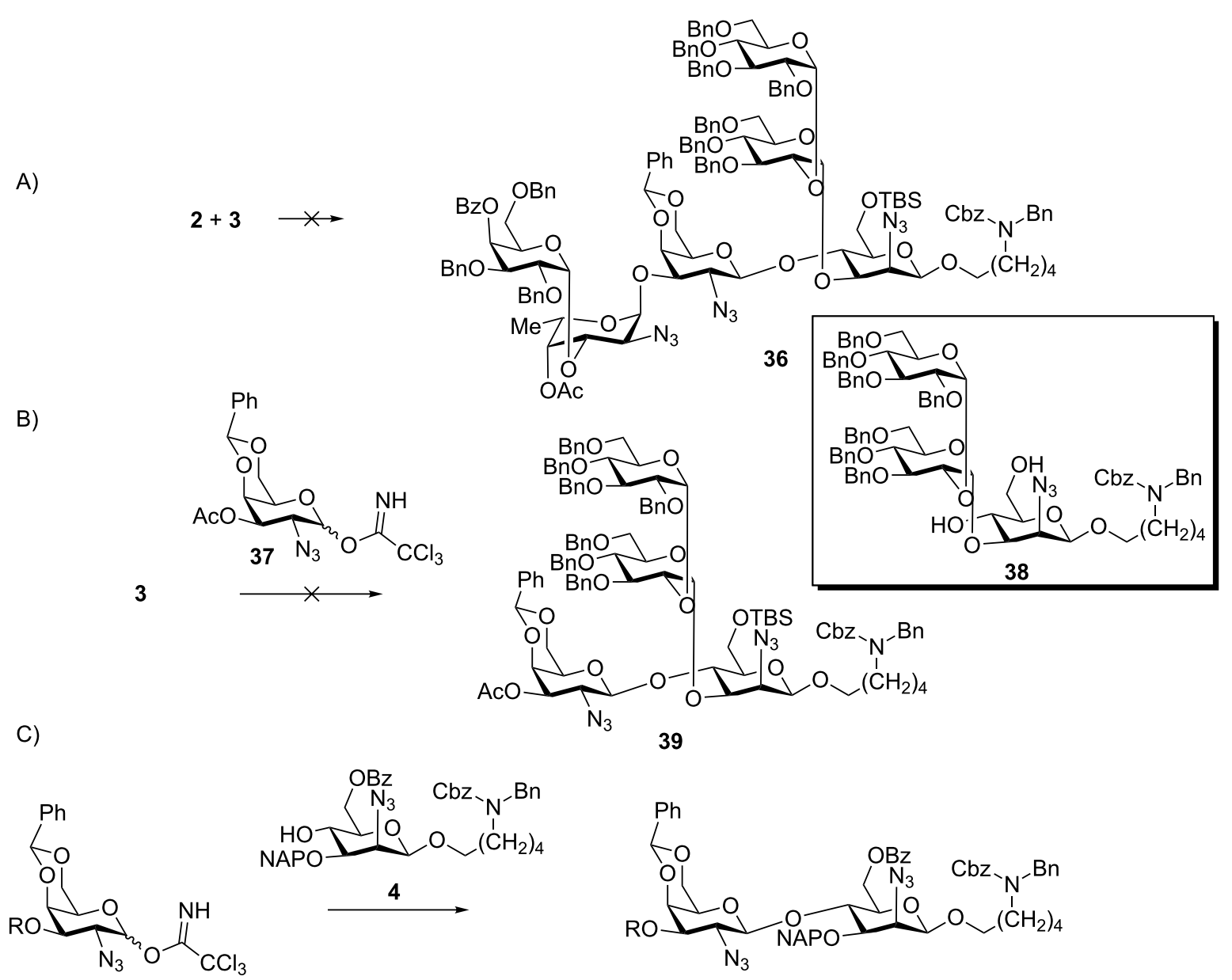

37: $R=A c$

5: $\mathrm{R}=\mathrm{Bz}$

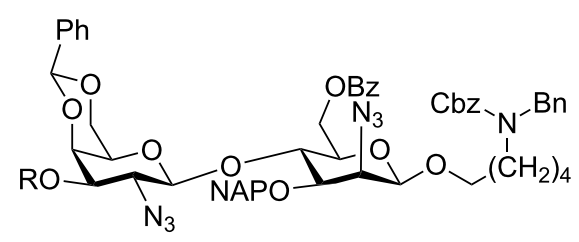

40: $R=A c(21 \%)$

41: $R=B z(37 \%)$ 
tected mannosazide $\mathbf{4}$ served as the starting point for stepwise assembly from the reducing to the non-reducing end (Scheme 8). Union of $\mathbf{4}$ and 5 (Scheme 7) produced disaccharide $\mathbf{4 1}$ as the key intermediate, the naphthyl protecting group of which was cleaved in 70\% yield using DDQ [37] to afford 42. Thioglycoside $\mathbf{4 3}$ failed to react with disaccharide $\mathbf{4 2}$ to furnish the desired trisaccharide 44. Considering a potential "mismatch" [38] between the thioglycoside glycosylating agent and the acceptor $[39,40]$ we explored whether the glucosyl tri- chloroacetimidate donor $\mathbf{6}$ (Scheme 1) would be more suitable. Indeed, glycosylation of disaccharide $\mathbf{4 2}$ with building block $\mathbf{6}$ using TMSOTf as the activator proceeded to produce trisaccharide 44 in $65 \%$ yield.

Removal of the C2 naphthyl ether using DDQ provided acceptor $\mathbf{4 5}$, which in turn was reacted with glucosyl thioglycoside 7 in the presence of NIS and TfOH to produce $\alpha$-linked tetrasaccharide 46 in $62 \%$ yield (Scheme 8 ). At this stage, the

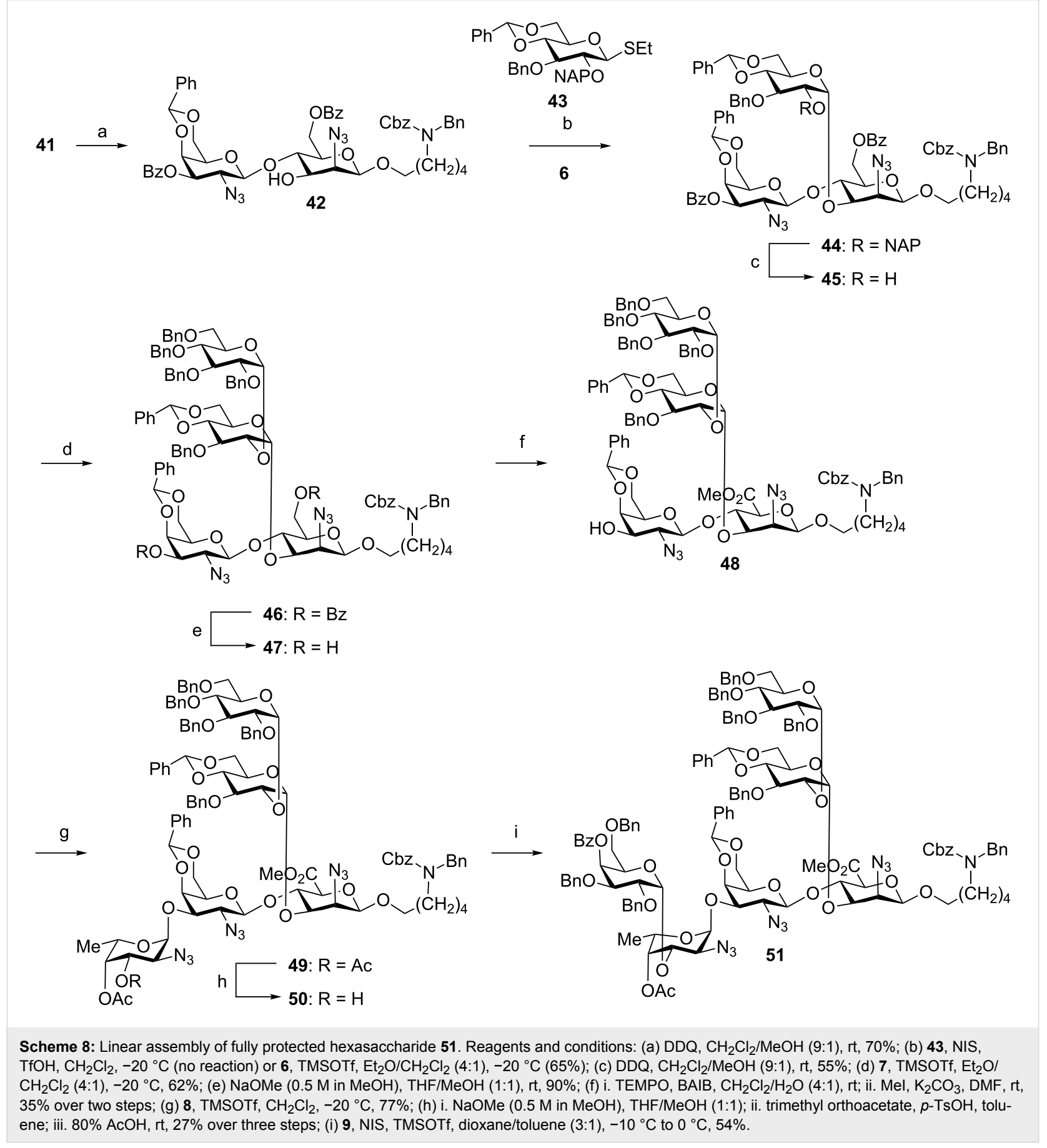


2-azidomannose moiety of $\mathbf{4 6}$ was converted to the corresponding mannosaminuronic acid by cleaving the C6 benzoate ester using sodium methoxide in methanol and selective oxidation of the primary alcohol of $\mathbf{4 7}$ using BAIB/TEMPO. Tetrasaccharide acceptor 48 was obtained by esterification of the carboxylic acid under basic conditions using methyl iodide in $32 \%$ yield over three steps [41]. Next, TMSOTf activation of fucosyl trichloroacetimidate $\mathbf{8}$ (Scheme 1) catalyzed the glycosylation of methyl uronate 48 to afford pentasaccharide 49 exclusively as the $\alpha$-isomer by virtue of remote participation of the 3 - $O$-acetate group. In anticipation of the final glycosylation, the fucosazide moiety of 49 was converted into acceptor 50. The desired hexasaccharide 51 was obtained as the $\alpha$-anomer in $54 \%$ yield by coupling galactose building block 9 (Scheme 1) to pentasaccharide 50 using NIS/TfOH in a mixture of toluene/dioxane. Again, the $\mathrm{C} 4$ benzoate ester of 9 ensured high selectivity for the desired cis-glycosidic linkage.

Global deprotection commenced with the conversion of the three azide groups present in compound $\mathbf{5 1}$ into NHAc groups in a single step using thioacetic acid in pyridine [42] afforded triacetamide 52 in $65 \%$ yield; it is important to note that $\mathrm{Zn}$-mediated reduction of $\mathbf{5 1}$ led to decomposition of the substrate. Ester saponification of $\mathbf{5 2}$ employing sodium methoxide in methanol yielded none of the desired product $\mathbf{5 3}$ but rather the tentatively assigned $\beta$-elimination products $\mathbf{5 4}$ and $\mathbf{5 5}$. Furthermore, an attempt at employing a more nucleophilic and less basic reagent such as a lithium hydroxide/hydrogen peroxide mixture did not provide relief from the problem, but instead also produced a mixture of undesired products. Adjustments in the sequence of deprotection steps by first carrying out hydrogenolysis using $\mathrm{Pd} / \mathrm{C}$ in a mixture of $\mathrm{AcOH} / \mathrm{H}_{2} \mathrm{O} / t-\mathrm{BuOH}$ prior to ester hydrolysis using $\mathrm{LiOH} / \mathrm{H}_{2} \mathrm{O}_{2}$ enabled the hexasaccharide 1 to be obtained in $37 \%$ yield (Scheme 9).

\section{Conclusion}

The first total synthesis of the S. pneumoniae serotype 12F capsular polysaccharide repeating unit hexasaccharide $\mathbf{1}$ was achieved by means of a linear approach. A convergent [3 +3$]$ total synthesis strategy failed, most likely due to steric crowding around the trisaccharide acceptor. The synthesis of $\mathbf{1}$ is an illustrative example of the challenges associated with state-of-the-art oligosaccharide assembly including steric, conformational, remote participation groups and solvent effects. It lends further credence to the linear assembly concept in which one monosaccharide unit at a time is incorporated, and which serves as the basis for automated glycan assembly [43]. With the synthetically sourced hexasaccharide repeating unit in hand detailed

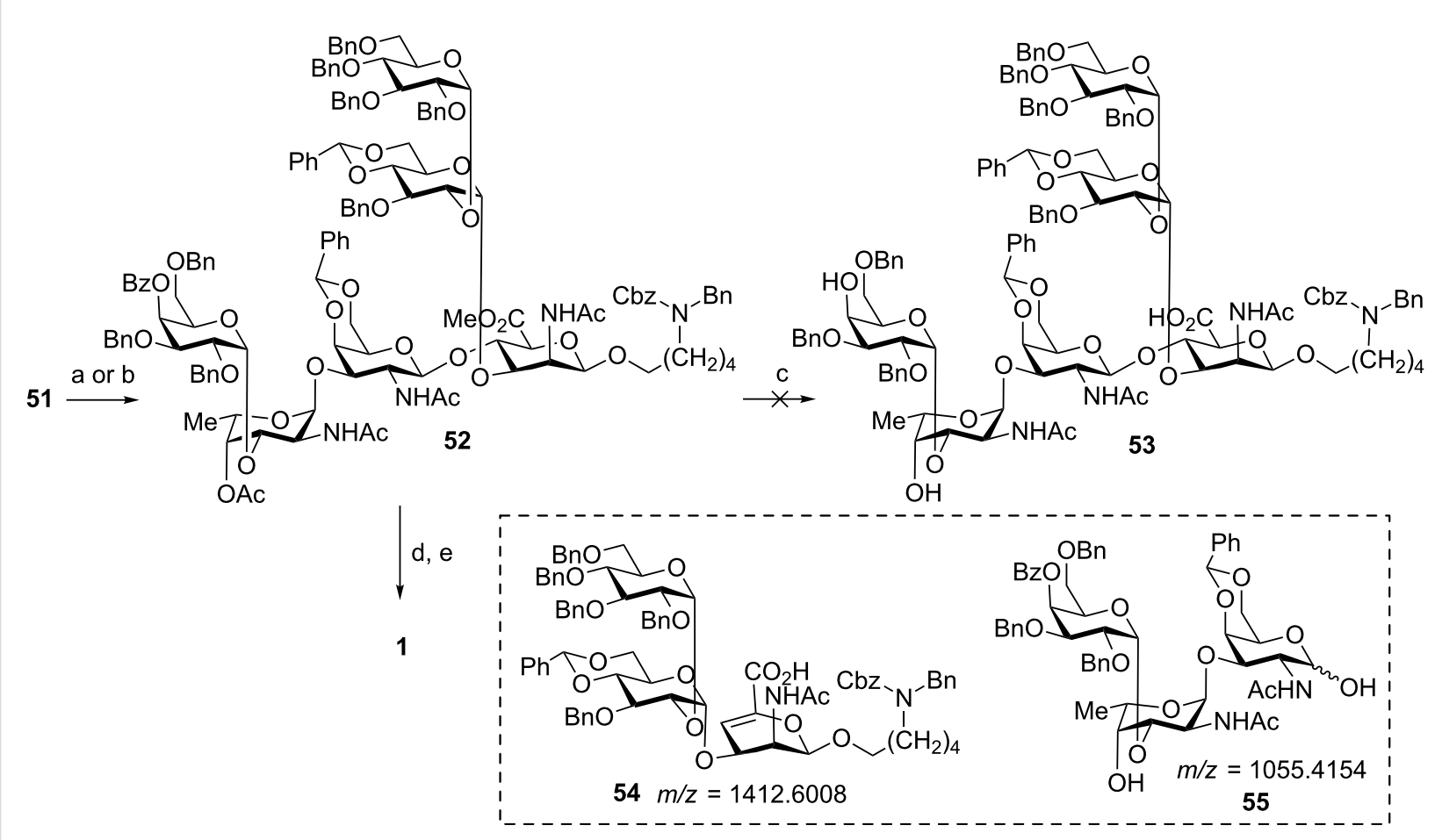

Scheme 9: Global deprotection to furnish S. pneumonia serotype $12 \mathrm{~F}$ repeating unit hexasaccharide 1. Reagents and conditions: (a) thioacetic acid, pyridine, rt, $65 \%$; (b) $\mathrm{Zn}, \mathrm{AcOH} / \mathrm{Ac}_{2} \mathrm{O} / \mathrm{THF}, \mathrm{Cu}_{2} \mathrm{SO}_{4}$ (aq, decomposed); saponification conditions that lead to $\beta$-elimination (c) i. $\mathrm{NaOMe}(0.5 \mathrm{M}$ in $\mathrm{MeOH}$ ) in $\mathrm{MeOH}$, ii. $\mathrm{NaOH}\left(4 \mathrm{M}, 2 \mathrm{M}, 1 \mathrm{M}, 0.5 \mathrm{M}, 0.1 \mathrm{M}\right.$ ) solution in THF, iii. $\mathrm{H}_{2} \mathrm{O}_{2}, \mathrm{LiOH}, \mathrm{THF}, \mathrm{H}_{2} \mathrm{O}$; successful sequence (d) $\mathrm{Pd} / \mathrm{C}, \mathrm{AcOH}, \mathrm{H} \mathrm{O} \mathrm{O}$, $t$ - $\mathrm{BuOH}(\mathrm{e}) \mathrm{H}_{2} \mathrm{O}_{2}$, LiOH, THF, $\mathrm{H}_{2} \mathrm{O}, 37 \%$ over two steps. 
immunological analysis of $S$. pneumoniae serotype $12 \mathrm{~F}$ can be undertaken, and future work will address the expanded inclusion of this antigen in next-generation glycoconjugate vaccines.

\section{Abbreviations}

Ac: acetate ester; BAIB: bis(acetoxy)iodobenzene; Bz: benzoyl; CPS: capsular polysaccharide; DMF: $N, N$-dimethylformamide; EtOAc: ethyl acetate; GlcA: glucouronic acid; HPLC: highperformance liquid chromatography; Lev: levulinoyl; MALDI-TOF MS: matrix-assisted laser desorption/ ionization-time of flight mass spectrometry; NAP: 2-naphthylmethyl; TBS: tert-butyldimethylsilyl; THF: tetrahydrofuran; TMSOTf: trimethylsilyl trifluoromethanesulfonate.

\section{Supporting Information}

\section{Supporting Information File 1}

Experimental details and full characterization data of all new compounds.

[http://www.beilstein-journals.org/bjoc/content/ supplementary/1860-5397-13-19-S1.pdf]

\section{Acknowledgements}

We thank the Max Planck Society and the Körber Foundation (Award to P.H.S.) for generous financial support and Dr. Allison Berger for editing the manuscript.

\section{References}

1. Friedländer, C. Fortschr. Med. 1883, 1, 715-733.

2. Pasteur, L. Bull. Acad. Med. (Paris, Fr.) 1881, 10, 94-103.

3. Sternberg, G. M. Nat. Board Health Bull. 1881, 2, 781-783.

4. Musher, D. M. Clin. Infect. Dis. 1992, 14, 801-809. doi:10.1093/clinids/14.4.801

5. O'Brien, K. L.; Wolfson, L. J.; Watt, J. P.; Henkle, E.; Deloria-Knoll, M.; McCall, N.; Lee, E.; Mulholland, K.; Levine, O. S.; Cherian, T. Lancet 2009, 374, 893-902. doi:10.1016/S0140-6736(09)61204-6

6. Henrichsen, J. J. Clin. Microbiol. 1995, 33, 2759-2762.

7. Lund, E.; Henrichsen, J. Laboratory Diagnosis, Serology and Epidemiology of Streptococcus pneumoniae. In Methods in Microbiology; Bergan, T.; Norris, J. R., Eds.; Academic Press, 1978; Vol. 12, pp 241-262.

8. Reeves, R. E.; Goebel, W. E. J. Biol. Chem. 1941, 139, 511-519.

9. Moxon, E. R.; Kroll, J. S. Curr. Top. Microbiol. Immunol. 1990, 150, 65-85. doi:10.1007/978-3-642-74694-9_4

10. Austrian, R. Clin. Infect. Dis. 1981, 3 (Suppl. S1), S1-S17. doi:10.1093/clinids/3.Supplement_1.S1

11. Austrian, R. Clin. Infect. Dis. 1989, 11 (Suppl. S3), S598-S602. doi:10.1093/clinids/11.Supplement_3.S598

12. Committee on Infectious Diseases. Pediatrics 2010, 126, 186-190.

13. Plosker, G. L. Pediatr. Drugs 2013, 15, 403-423. doi:10.1007/s40272-013-0047-z
14. Park, I. H.; Pritchard, D. G.; Cartee, R.; Brandao, A.; Brandileone, M. C. C.; Nahm, M. H. J. Clin. Microbiol. 2007, 45, 1225-1233. doi:10.1128/JCM.02199-06

15. Heidelberger, M.; Avery, O. T. J. Exp. Med. 1924, 40, 301-316. doi:10.1084/jem.40.3.301

16. Calix, J. J.; Nahm, M. H. J. Infect. Dis. 2010, 202, 29-38. doi:10.1086/653123

17. Robbins, J. B.; Austrian, R.; Lee, C. J.; Rastogi, S. C.; Schiffman, G.; Henrichsen, J.; Makela, P. H.; Broome, C. V.; Facklam, R. R.; Tiesjema, R. H.; Parke, J. C. J. Infect. Dis. 1983, 148, 1136-1159. doi:10.1093/infdis/148.6.1136

18. Rodgers, G. L.; Arguedas, A.; Cohen, R.; Dagan, R. Vaccine 2009, 27, 3802-3810. doi:10.1016/j.vaccine.2009.04.021

19. Oberli, M. A.; Tamborrini, M.; Tsai, Y.-H.; Werz, D. B.; Horlacher, T.; Adibekian, A.; Gauss, D.; Möller, H. M.; Pluschke, G.; Seeberger, P. H. J. Am. Chem. Soc. 2010, 132, 10239-10241. doi:10.1021/ja104027w

20. Werz, D. B.; Seeberger, P. H. Angew. Chem., Int. Ed. 2005, 44, 6315-6318. doi:10.1002/anie.200502615

21. Tamborrini, M.; Werz, D. B.; Frey, J.; Pluschke, G.; Seeberger, P. H. Angew. Chem., Int. Ed. 2006, 45, 6581-6582. doi:10.1002/anie.200602048

22. Johnson, M. A.; Pinto, B. M. J. Am. Chem. Soc. 2002, 124, 15368-15374. doi:10.1021/ja020983v

23. Yu, X. H.; Sun, Y.; Frasch, C.; Concepcion, N.; Nahm, M. H. Clin. Diagn. Lab. Immunol. 1999, 6, 519-524.

24. Codée, J. D. C.; Christina, A. E.; Walvoort, M. T. C.; Overkleeft, H. S.; van der Marel, G. A. Uronic Acids in Oligosaccharide and Glycoconjugate Synthesis. In Reactivity Tuning in Oligosaccharide Assembly; Fraser-Reid, B.; Cristóbal López, J., Eds.; Springer-Verlag: Berlin, 2011; Vol. 301, pp 253-289. doi:10.1007/128_2010_111

25. van den Bos, L. J.; Codée, J. D. C.; Litjens, R. E. J. N.; Dinkelaar, J.; Overkleeft, H. S.; van der Marel, G. A. Eur. J. Org. Chem. 2007, 3963-3976. doi:10.1002/ejoc.200700101

26. Lefeber, D. J.; Kamerling, J. P.; Vliegenthart, J. F. G. Chem. - Eur. J. 2001, 7, 4411-4421.

doi:10.1002/1521-3765(20011015)7:20<4411::AID-CHEM4411>3.0.C O;2-T

27. Allevi, P.; Paroni, R.; Ragusa, A.; Anastasia, M. Tetrahedron: Asymmetry 2004, 15, 3139-3148. doi:10.1016/j.tetasy.2004.08.006

28. de Jong, A.-R.; Hagen, B.; van der Ark, V.; Overkleeft, H. S.; Codée, J. D. C.; van der Marel, G. A. J. Org. Chem. 2012, 77, 108-125. doi:10.1021/jo201586r

29. Polat, T.; Wong, C.-H. J. Am. Chem. Soc. 2007, 129, 12795-12800. doi:10.1021/ja073098r

30. Wang, Z.; Xu, Y.; Yang, B.; Tiruchinapally, G.; Sun, B.; Liu, R.; Dulaney, S.; Liu, J.; Huang, X. Chem. - Eur. J. 2010, 16, 8365-8375. doi:10.1002/chem.201000987

31. Wu, X.; Cui, L.; Lipinski, T.; Bundle, D. R. Chem. - Eur. J. 2010, 16, 3476-3488. doi:10.1002/chem.200902460

32. Kramer, S.; Nolting, B.; Ott, A.-J.; Vogel, C. J. Carbohydr. Chem. 2000, 19, 891-921. doi:10.1080/07328300008544125

33. Daragics, K.; Fügedi, P. Tetrahedron Lett. 2009, 50, 2914-2916. doi:10.1016/j.tetlet.2009.03.194

34. Eller, S.; Collot, M.; Yin, J.; Hahm, H. S.; Seeberger, P. H. Angew. Chem., Int. Ed. 2013, 52, 5858-5861. doi:10.1002/anie.201210132

35. Demchenko, A. V.; Rousson, E.; Boons, G.-J. Tetrahedron Lett. 1999, 40, 6523-6526. doi:10.1016/S0040-4039(99)01203-4 
36. Weishaupt, M. W.; Matthies, S.; Seeberger, P. H. Chem. - Eur. J. 2013, 19, 12497-12503. doi:10.1002/chem.201204518

37. BeMiller, J. N.; Kumari, G. V. Carbohydr. Res. 1972, 25, 419-428. doi:10.1016/S0008-6215(00)81653-5

38. Walvoort, M. T. C.; Volbeda, A. G.; Reintjens, N. R. M.; van den Elst, H.; Plante, O. J.; Overkleeft, H. S.; van der Marel, G. A.; Codée, J. D. C. Org. Lett. 2012, 14, 3776-3779. doi:10.1021/ol301666n

39. Fraser-Reid, B.; Cristobal Lopez, J.; Radhakrishnan, K. V.; Mach, M.; Schlueter, U.; Gomez, A.; Uriel, C. Can. J. Chem. 2002, 80, 1075-1087. doi:10.1139/v02-137

40. Fraser-Reid, B.; Cristóbal López, J.; Gómez, A. M.; Uriel, C. Eur. J. Org. Chem. 2004, 1387-1395. doi:10.1002/ejoc.200300689

41. Walvoort, M. T. C.; Lodder, G.; Overkleeft, H. S.; Codée, J. D. C.; van der Marel, G. A. J. Org. Chem. 2010, 75, 7990-8002. doi:10.1021/jo101779v

42. Shangguan, N.; Katukojvala, S.; Greenberg, R.; Williams, L. J. J. Am. Chem. Soc. 2003, 125, 7754-7755. doi:10.1021/ja0294919

43. Seeberger, P. H. Acc. Chem. Res. 2015, 48, 1450-1463. doi:10.1021/ar5004362

\section{License and Terms}

This is an Open Access article under the terms of the Creative Commons Attribution License (http://creativecommons.org/licenses/by/4.0), which permits unrestricted use, distribution, and reproduction in any medium, provided the original work is properly cited.

The license is subject to the Beilstein Journal of Organic Chemistry terms and conditions:

(http://www.beilstein-journals.org/bjoc)

The definitive version of this article is the electronic one which can be found at: doi:10.3762/bjoc. 13.19 